\title{
DIRETRIZES PROJETUAIS PARA UM ESPAÇO DE LAZER EM BAIRROS DE BAIXA RENDA EM ÁLVARES MACHADO - SP
}

Ana Paula Tardin Rodrigues, Mayara Pissutti Albano, Yeda Ruiz Maria

Universidade do Oeste Paulista - UNOESTE, curso de Arquitetura e Urbanismo, Presidente Prudente, SP. E-mail: paula rodrigues28@hotmail.com

\section{RESUMO}

Este trabalho tem como objetivo a proposição de diretrizes projetuais para um projeto urbanístico destinado ao lazer e ao incentivo do convívio entre os moradores dos bairros Jardim Panorama e Parque dos Pinheiros I e II, em Álvares Machado - SP. Elegeu-se uma área localizada entre os bairros Jardim Panorama e Parque dos Pinheiros I, que foi ocupada pela favela do Saci, hoje já demolida. A área que ao longo deste processo passou por intervenções, encontra-se em estado de degradação socioambiental, além de contribuir no aumento da insegurança para o local e na desvalorização da paisagem urbana. Tem-se então a justificativa da escolha do local, na intenção de promover melhorias na qualidade de vida dos moradores e na revitalização desta área. Como método de pesquisa qualitativa, foram realizados estudos com revisão bibliográfica sobre o tema, pesquisas documentais e levantamentos in loco na escala do bairro, analisando suas potencialidades e problemáticas sob a lente de diferentes leituras, relacionadas com a proposta do trabalho.

Palavras-chave: Área de Lazer. Parque Urbano. Jardim Panorama. Parque dos Pinheiros. Álvares Machado.

PROJECT GUIDELINES FOR A LEISURE SPACE IN LOW INCOME DISTRICTS IN ÁLVARES MACHADO SP

\section{ABSTRACT}

The objective of this work is to propose design guidelines for an urban development project for leisure and the encouragement of social interaction among residents of Jardim Panorama and Parque dos Pinheiros I and II districts in Álvares Machado - SP. An area was chosen between the neighborhoods Jardim Panorama and Parque dos Pinheiros I, which was occupied by the Saci favela, now demolished. The area that has undergone interventions during this process is in a state of socio-environmental degradation, in addition to contributing to the increase of insecurity for the place and the devaluation of the urban landscape. The justification of the choice of the place is then intended to promote improvements in the quality of life of the residents and in the revitalization of this area. As a qualitative research method, studies were carried out with a bibliographical review on the subject, documentary surveys and surveys in loco at the neighborhood scale, analyzing their potentialities and problems under the lens of different readings related to the work proposal.

Keywords: Recreation Area. Urban Park. Jardim Panorama. Parque dos Pinheiros. Álvares Machado.

\section{INTRODUÇÃO}

O lazer para integração socioespacial significa um espaço público com qualidade, que deve ser pensado para um bem comum, onde os usuários como protagonistas deste espaço devem se 
relacionar diretamente com ele e toda a sociedade onde ele está inserido. Para que o lazer seja desenvolvido no meio urbano, faz-se necessário o planejamento de áreas livres apropriadas para tal, fato que nem sempre ocorre, visto que, segundo Patlajan (1978) sua importância não é destacada.

A cidade de Álvares Machado - SP desenvolvia-se paulatinamente, quando em 1978, o momento político especulava o prolongamento da Rodovia Castelo branco até a região, cortando as periferias da cidade de Álvares Machado, exatamente onde hoje estão localizados os bairros Jardim Panorama e Parque dos Pinheiros I e II foco de estudo deste trabalho (KAHALE; RAFAEL; RODRIGUES, 1996).

Conforme Kahale, Rafael e Rodrigues (1996), o Jardim Panorama foi o primeiro a ser loteado e a Câmara Municipal de Álvares Machado já discutia sobre as problemáticas que este loteamento enfrentaria, nos âmbitos sociais e econômico causado principalmente pela falta de infraestrutura regulamentada. Estes bairros hoje formam uma aglomeração urbana de tamanho significativo, distando $08 \mathrm{~km}$ do centro da cidade de Álvares Machado e enfrentam problemas, anteriormente já previstos pelo poder público municipal com a falta de infraestrutura urbana (MIYAZAKI, 2005).

Neste sentido, o local escolhido como objeto de estudo é uma área verde pública, localizada entre os bairros Jardim Panorama e Parque dos Pinheiros I. Atualmente não há estrutura para o desenvolvimento de atividades de lazer, está repleto de vegetação formada por conjuntos arbóreos e grama, possui um córrego em seu interior que encontra-se em processo de assoreamento e contendo resíduos sólidos depositados no leito do canal.

Em concordância com os autores Sitte (1992) e Guzzo (1999), Lamas (1993) afirma que, as áreas verdes trazem vários benefícios para o meio urbano, proporcionando espaços onde as pessoas podem usufruir destas áreas para o lazer e seu bem-estar de modo geral.

Esta área verde pública abrigou há mais 12 anos cerca de 60 famílias, que ocuparam a área formando a favela do Saci, onde a Prefeitura Municipal levou até o local infraestruturas como de abastecimento de água e energia elétrica (KAHALE; RAFAEL; RODRIGUES, 1996). A favela foi demolida e atualmente esta área encontra-se já desocupada, passando por um processo de degradação socioambiental, contribuindo apenas com o aumento de insegurança para os locais de seu entorno imediato.

Desta forma justifica-se a proposta de formulação de diretrizes para um projeto urbanístico de uma área de lazer, buscando propor integração e convívio social entre os moradores dos bairros periféricos Jardim Panorama e Parque dos Pinheiros I e II e assim também promover melhoria na urbanização desta área.

\section{METODOLOGIA}

O presente trabalho tem como metodologia de pesquisa, a análise qualitativa, que foi desenvolvida em segmentos como: revisão bibliográfica, pesquisas documentais da história da cidade de Álvares Machado e a inserção dos bairros Jardim Panorama e Parque dos Pinheiros I e II na malha urbana, levantamentos físicos territoriais in loco.

\section{ESPAÇOS DE LAZER URBANOS}

Diferentes autores têm conceituado o termo lazer e são inúmeras as definições sobre o assunto entre eles.

Dumazedier (2001) afirma que além das atividades de distração, recreação e entretenimento, o lazer também é o tempo estar longe de toda informação desinteressada, ou seja, aquelas relacionadas ao meio de trabalho. Para Requixa (1980) o lazer é uma ocupação que 
proporciona a recuperação psicossomática, além do desenvolvimento pessoal e social dos indivíduos, e possui um caráter de livre escolha e de não obrigatoriedade.

Já o autor Marcellino (2006) completa, classificando e dividindo as atividades de lazer em três eixos básicos do lazer, que, de acordo com o autor são: o tempo de não trabalho, o espaço de sua vivência e a atitude do indivíduo. Esses três eixos são os pilares do lazer e isso demonstra que o lazer está ligado à várias áreas de atuação do homem, ou seja, o lazer tem uma função importante na vida do ser humano.

Stadnik (2002) afirma que há a necessidade de equilíbrio entre os tempos sociais, ou seja, o tempo de trabalho e o tempo livre, onde no tempo livre, é o momento em que o lazer, principalmente o lazer criativo, se desenvolve. O lazer é de extrema importância ao ser humano, recompondo suas energias, ampliando inclusive sua capacidade criativa, melhorando sua autoestima e aumentando a satisfação pessoal (MARCELLINO, 2006).

Os espaços livres são considerados importantes pra Del Rio (1990) pelas relações que estes possuem no contexto urbano e as atividades sociais que estes desempenham, dentre elas, as atividades de lazer.

Mascaró (2007) corrobora o pensamento do autor destacando ainda os benefícios que os espaços públicos abertos de lazer trazem para o ambiente urbano, além das possibilidades das práticas sociais, momentos de lazer, encontros ao ar livre e manifestações de vida urbana e comunitária, contribuindo para o desenvolvimento do ser humano e interação entre eles.

\section{ÁREA DE LAZER ENTRE OS BAIRROS JARDIM PANORAMA E PARQUE DOS PINHEIROS I E II}

Álvares Machado está localizada na 10å. Região Administrativa do Estado de São Paulo, no Oeste do Estado e corresponde a uma área de 327,75 km2 de extensão territorial (Figura 45). Sua população foi estimada em 23.513 habitantes, segundo o censo de 2010 do Instituto Brasileiro de Geografia e Estatística - IBGE, com densidade demográfica de 37,7 hab/ $\mathrm{km}^{2}$.

Segundo Takenaka (2003), inicialmente o município foi denominado como Brejão e teve como fundador Manoel Francisco de Oliveira, em 19 de março de 1916. Seu desenvolvimento local se deu pela chegada da Estrada de Ferro Sorocabana no ano de 1919. Em 1927, Álvares Machado foi elevada a Distrito da Paz, onde passou a pertencer ao município de Presidente Prudente e somente em 30 de novembro de 1944 emancipou-se.

Na década de 1970, o município machadense apresentou significativa expansão territorial com implantação de novos loteamentos que diferenciou-se de forma expressiva se comparada com as décadas anteriores, trazendo impactos negativos em relação a localização desses diversos parcelamentos que ao invés de contribuir para um processo reversivo de compactação do tecido urbano, parecem ter ratificado o desordenamento urbanístico (SILVA JUNIOR, 2007). Dentre estes, estão o Jardim Panorama e o Parque dos Pinheiros I e II, localizados na zona Leste de Álvares Machado e escolhidos como objeto de estudo.

Os bairros estudados localizam-se na periferia do município de Álvares Machado - SP (Figura 1), distantes da malha urbana consolidada e apresentam desigualdades significativas em sua urbanização se comparado com outras áreas consolidadas da cidade. 
Figura 1 - Localização dos bairros Jardim Panorama e Parque dos Pinheiros I e II

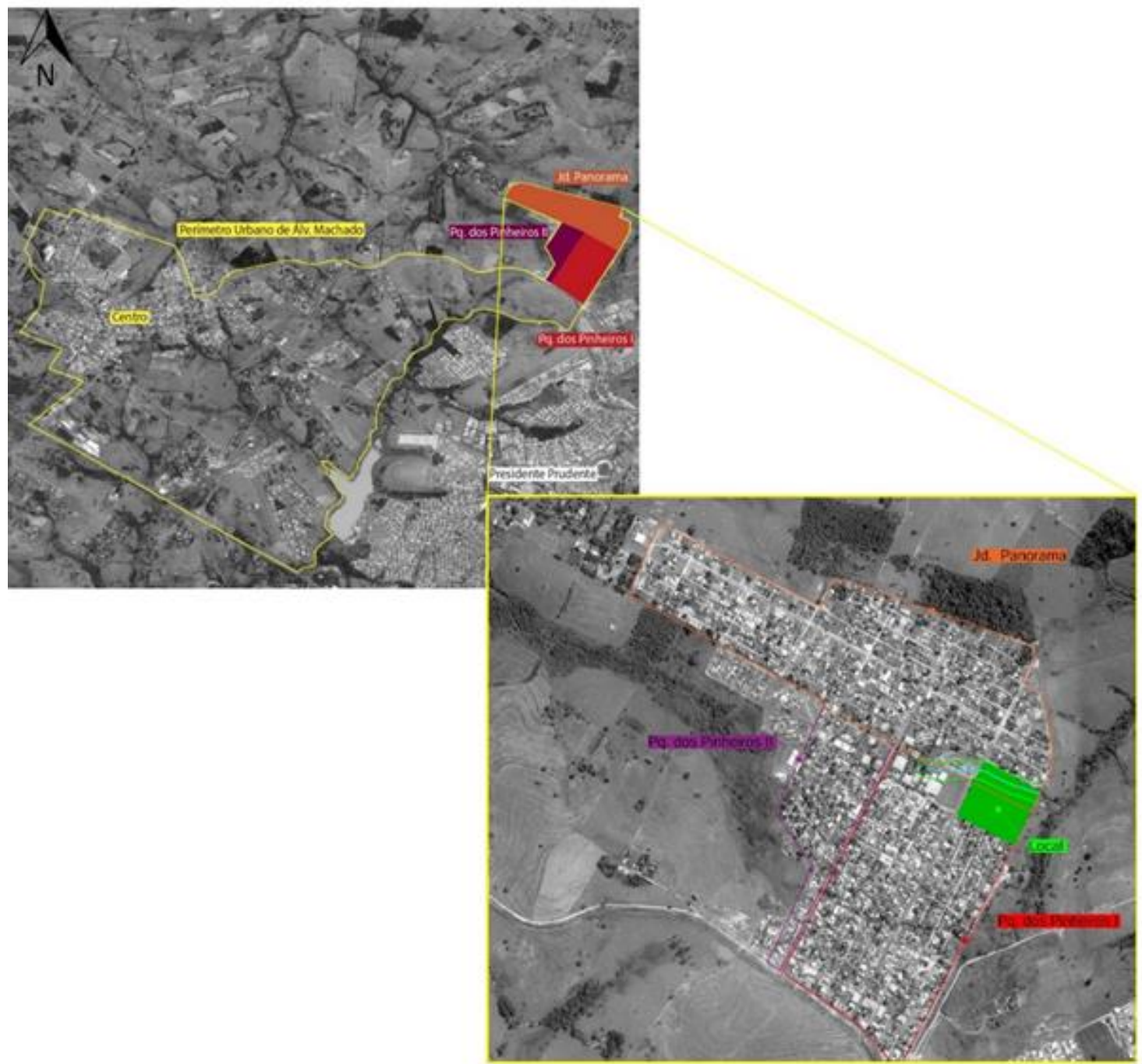

Fonte: Google Maps, Modificado pelos autores, 2017.

Estes bairros foram loteados, ainda que já previsto as problemáticas que os mesmos enfrentariam pela longa distância até a cidade e por falta de infraestrutura e por sofrerem pela falta de pavimentação nas ruas, dificultando a ida até o centro em dias de chuva na busca de serviços não encontrados nos bairros.

Sendo assim, os bairros citados são marcados pela desigualdade social, fortalecida pelo fato de serem segregados. Os habitantes residentes nos bairros citados são de baixa renda, e possuem índices elevados de pobreza em relação a outras áreas da cidade. Diante desta realidade, Kahale, Rafael e Rodrigues (1996) afirmam que ao implantar estes loteamentos, os incorporadores já previam que estes seriam destinados para atender a uma população de baixa renda.

Tais características reforçam a necessidade de diretrizes para um espaço de lazer em uma área verde, por onde passa um córrego e por isso, tem uma Área de Preservação Permanente APP demarcada, localizada entre os bairros estudados, que representará uma melhora na oferta de equipamentos urbanos nesta área segregada e excluída.

De acordo com os resultados obtidos nos estudos de Kahale; Rafael e Rodrigues (1996) realizados nos bairros Jardim Panorama e Parque dos Pinheiros I e II, os espaços de lazer praticamente são inexistentes nos referidos bairros, gerando desconforto nos moradores pela falta de espaço apropriado ao entretenimento comunitário. Os autores continuam dizendo que 
para esta população, o lazer está associado em jogar bola no campo de futebol localizado no Parque dos Pinheiros I e visitar amigos e parentes aos finais de semana.

A partir das identificações realizadas nos bairros Jardim Panorama e Parque dos Pinheiros I sobre os espaços de lazer existentes, foi possível observar que os bairros apresentam carência de espaços de lazer, ratificando, desta forma, as diretrizes para um espaço de lazer, objetivo geral do presente trabalho.

\section{DIRETRIZES PARA ÁREA DE LAZER}

Para conformar as diretrizes para o espaço de lazer, considerou-se as questões não só arquitetônicas, mas também as sociais, culturais, econômicas e ambientais, a fim de atrair pessoas e oferecer boa qualidade ao seu caráter. Para isto, as diretrizes projetuais se pautaram na observação da área de estudo, atentando-se ao que se passa atualmente no local, através de um levantamento sobre os equipamentos de lazer existentes nos bairros estudados, demonstrando a necessidade da população por espaços de lazer.

Para o projeto do parque é necessário que o mesmo promova o lazer e a sociabilização entre os usuários, para isto, optou-se por utilizar de meios facilitadores como elementos norteadores. Além disso, os estudos do local revelam a importância da área verde, considerada, assim, um orientador essencial, já que esta assim como outros elementos referenciam a paisagem e a identidade do local (Figura 2).

Após serem apresentadas as diretrizes projetuais, vê-se a importância que as mesmas trazem para o desenvolvimento do projeto, onde irão auxiliar a condução do mesmo, de maneira com que o espaço de lazer tenha tamanha importância e uso pelos moradores, assim como proposto. 
Figura 2 - Diretrizes projetuais através de elementos norteadores

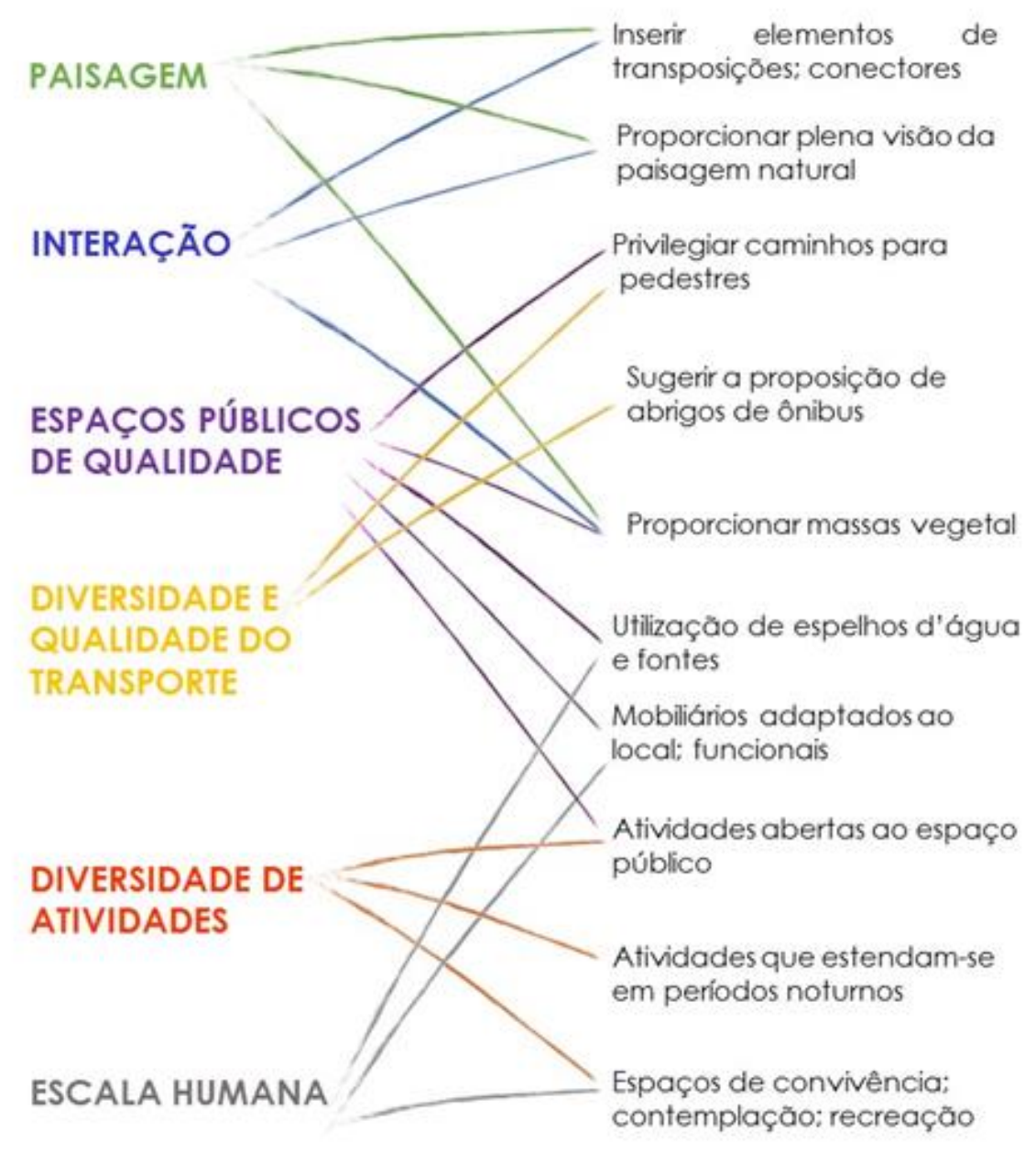

Fonte: Elaborado pelas autoras (2017).

\section{CONCLUSÃO}

Tomando por base os estudos realizados, conclui-se que as diretrizes elaboradas para um projeto urbanístico de lazer e recreação em uma área verde com a existência de uma APP auxiliarão para um projeto com potencialidades de melhorias para esta área, mantendo o devido respeito por este espaço e preocupação ambiental. Com base nestes interesses, a área receberá um tratamento voltado para sua relevante característica ambiental, proporcionando sua reestruturação ecológica, através do reflorestamento do córrego, recuperando sua vegetação ciliar e atitudes de projeto com a criação de espaços verdes no parque. Assim, acredita-se que a implantação de um parque nesta área atuará de forma benéfica, além de favorecer também a população pela possibilidade de aproximação com áreas verdes, considerando que esta relação contribui na qualidade de vida das pessoas.

\section{REFERÊNCIAS BIBLIOGRÁFICAS}

CALDEIRA, J. M. A praça brasileira - trajetória de um espaço urbano: origem e modernidade. 2007. Tese (Doutorado) - Instituto de Filosofia e Ciências Humanas, Universidade Estadual de Campinas - Campinas.

GEHL, J. Cidades para pessoas. 2. ed. São Paulo: Perspectiva, 2013. 262 p. 
GUZZO, P. Estudos dos espaços livres de uso público e da cobertura vegetal em área urbana da cidade de Ribeirão Preto - SP. 1999. 106f. Dissertação (Mestrado em Geociências) - Instituto de Geociências e Ciências Exatas, Universidade Estadual Paulista, Rio Claro. 1999.

KAHALE, M.; RAFAEL, S.; RODRIGUES, W. O fenômeno da aglomeração urbana de Álvares Machado e Presidente Prudente. 1996. 85 f. Monografia (Especialização) - Faculdade de Ciências e Tecnologia, Universidade Estadual Paulista, Campus de Presidente Prudente - SP.

LAMAS, J. M. R. G. Morfologia urbana e desenho da cidade. Lisboa: Fundação Calouste Gubenkian. Junta Nacional de Investigação Científica e Tecnológica, 1993.

MARCELLINO, N. C. Estudos de lazer: uma introdução. 4. ed. Campinas: Editora Autores Associados, 2006.

MIYAZAKI, K. V. Revista Electrônica de Geografia y Ciencias. O processo de aglomeração urbana: um estudo sobre Presidente Prudente e Álvares Machado no estado de São Paulo, Brasil, Barcelona, v. IX, n. 194, ago., 2005. Disponível em: <http://www.ub.edu/geocrit/sn/sn-194110.htm>. Acesso em: 05 mai. 2017.

PATLAJAN, T. Urbanização e Lazer. In: Cadernos de Lazer, n. 3, p.39-50, São Paulo: Brasiliense, 1978.

SILVA JUNIOR, J. J. A lógica contraditória da expansão territorial urbana em Álvares Machado SP: uma faceta da urbanização desigual. 2007. 104 f. Monografia - Universidade Estadual Paulista Faculdade de Ciências e Tecnologia, Presidente Prudente - SP.

SITTE, C. A construção das cidades segundo seus princípios artísticos. Tradução Ricardo Ferreira Henrique. São Paulo: Ática, 1992. 